\title{
Editorial \\ Missing out: The intergenerational ramifications of current social security arrangements
}

\author{
Caitlyn Lehmann, Jennifer Lehmann and Rachael Sanders
}

Neoliberal reforms and ring-wing ideologies have seen the ideal of the social security 'safety net' take a hammering in the UK, USA and Australia. While the gap between rich and poor has widened, and demand for welfare payments increased, politicians, certainly in Australia, have generally neglected low income families, preferring to twiddle the economic dials affecting middle and upper income earners instead. Of course, tussling over who pays tax, how much, what constitutes useful expenditure, and who receives welfare services and benefits is not new - these questions have attended the modern welfare state from its inception. But the welfare safety net that most of us, grudgingly or otherwise, concede to be necessary for collective social harmony is no longer proving as effective as we would wish. Even with a battered and frayed, but still ostensibly functional systems of welfare payment and support offered in Australia, the number of people experiencing perpetual disadvantage is rising, with intergenerational poverty - its increase and impacts on children - of particular concern.

In the USA, for example, the official poverty rate stands at 12.7 percent, based on the US Census Bureau's 2016 estimates. In 2016, 'an estimated 43.1 million Americans lived in poverty according to the official measure. According to supplemental poverty measure, the poverty rate was 14.0 percent' (Centre for Poverty Research, 2017). In Britain, ' $7.3 \%$ of the UK population were experiencing persistent poverty, equivalent to roughly 4.6 million people' according to the Office for National Statistics, which defines persistent poverty as 'experiencing relative low income in the current year, as well as at least 2 out of the 3 preceding years' (Office for National Statistics, 2017). The Australian situation is no better. In October 2016, 'ACOSS released a new report revealing that poverty is growing in Australia, with an estimated 2.9 million people or $13.3 \%$ of all people living below the internationally accepted poverty line' (Australian Council of Social Services, 2018). It is not likely that the Australian situation has improved given the increasing gap between those with wealth and those without.

What is also clear, in Australia and elsewhere, is that welfare support has grown unreliable as a source of 'security', whether sought on a long-term or temporary basis. Some payments have become demonstrably inadequate for people's needs - Australia's unemployment benefit, Newstart, was considered inadequate even before 2012 and remains unchanged (Brennan, 2018). In too many instances, however, the problem is that the welfare safety net is experienced less like a trampoline protecting against indigence, than a nylon fishing net that ensnares individuals in bureaucracy or lets others simply slip through the mesh altogether. Just how arbitrary and precarious the welfare system is perceived to be was pointedly illustrated in the 2016 film I, Daniel Blake (Loach, 2016). Amid squabbling in the media over how'realistically' the film depicted the experience of poverty in 2010s Britain, what resonated powerfully for viewers in Britain, the US and Australia was the depiction of bureaucratic mechanisms that failed to provide a fair, timely and adequate response to the characters' needs. Put off work by his cardiologist, the titular Daniel Blake is forced into meeting stressful and humiliating job-seeker obligations while waiting weeks to appeal the rejection of his claim for a disability benefit. Meanwhile, single mum Katie, whom he befriends at the jobcentre, has her benefits suspended after arriving late for an appointment, and is forced to take extreme steps, including shoplifting and prostitution, to provide for her children.

Daniel's story, highlighting the consequences of income loss, the challenges faced when seeking financial support and the difficulties of regaining a 'normal' life, is representative of many people's experiences. Those who have had cause to seek financial support through Centrelink in Australia report similar challenges, ranging from difficulties in accessing forms and lodging applications in the first instance, to coping with unsubstantiated claims of 
overpayments, and demands for alleged overpayments to be repaid even when families are still dependent on benefits to get by (Karp \& Knaus, 2018). In late 2017, these issues gained national attention when the Australian federal government implemented its 'robo-debt' recovery scheme, hitting individuals with bills for hundreds or even thousands of dollars allegedly owed due to government overpayments. Although the onus placed on individuals to disprove the government's claims sparked community outcry, and served to focus media attention on the anonymous and adversarial nature of 'the system', the government continues to pursue its robo-debt measures.

Online forums are an obvious space where people can air their grievances with Centrelink and its overseas equivalents. However, mainstream media reports have also been attesting to the difficulties people are facing - and the negative experiences of families have been shared informally, too, with the editors of this journal. In a report on long call wait times for Centrelink, political reporter Dan Conifer (2018) cited one woman who said "Some days it's taken me an hour or two before I can even get through to Centrelink; I get the engaged tone ... And then when I do get through, often I'm on hold for an hour, if not more." Nearly 200 comments were posted in response to Conifer's story within the space of twenty-four hours, including the following examples:

So frustrating trying to communicate over the phone, I was eligible for a Low Income Healthcare Card after I had completed so much paperwork and submitted it in person last February 2017.... My Healthcare card arrived in August, 2017, 10 days after I actually received a phone call from Centrelink... How appalling is that for service... Not even nearly good enough... 24 Weeks (Chris14)

It is very obvious why the staff are so hard to contact. The government hopes to save large amounts of money that people are legally entitled to by making it so hard to get any help, people will give up and just suffer. I have found this when trying to help a friend with a brain injury. Every time she managed to complete the paperwork, they conveniently 'lost' it and she would have to start again. They have no disability support, and make it impossible for people with disabilities to navigate their horrendous 'paperwork'. (R. Giskard)

My wife has unsuccessfully tried to apply for her age pension at Centerlink [sic]. She is 70 years old. She was advised she had to apply online. After filling in numerous pages of information at home and at the MyGov offices on a few occasions and pressing SUBMIT the system crashed and she would have to start again. She still does not have a pension. It is an easy way for governments to control payments and minimise outgoings. Like my wife many people just give up. No one at the MyGov [sic] office was able to help or available. (Nik Ge)

Experiences shared in conversations with Children Australia's editors reflect similar frustrations with a system that actively impedes personal contact between claimants and claims assessors. Moreover, the accounts shared with Children Australia highlight a loss of confidence in the welfare benefits system, even among those who view themselves as competent to handle the system's demands.

It is becoming increasingly difficult to see a live person or lodge documents in person. You have to download things to your computer/phone and have the capacity to scan images or take photos to upload. If you do not have access to technology (especially a smartphone) then it is not easy or possible because you can no longer hand things in in person. The irony, when I tried to lodge something in person because the technology was driving me mad, was that they didn't allow me to hand something over the counter and recommended I use the technology 'at work' - 'work', the thing that most people at Centrelink do not have. Ironically amusing and frustrating. I just gave up and went without. (RS)

Eight weeks after I sent off a thick envelope with my application and supporting evidence for a healthcare card, I rang to see what was happening with the claim. When I finally got through on the call lines, I was told they hadn't received it. That it must have been 'lost in the post'. I couldn't believe it. All that effort, just wasted. The guy tried to help by walking me through a fresh online application. Halfway through, we discovered the system was defaulting to an earlier application that had already been rejected. He told me I'd have to wait a fortnight while the old application 'timed out' of the system, and he posted me a hardcopy application form in the meantime. I thought I could deal with Centrelink but this experience really shattered me. I still haven't been able to find the faith to start the claims process again. (CL)

The accounts shared with us and comments posted online explicitly capture an array of issues that put significant demands on people in terms of time and equipment costs, financial literacy, IT access and competence, and perseverance and energy. These are demands that those on low incomes frequently struggle to meet when they are experiencing financial insecurity and stress.

In the meantime, middle and upper income groups in society continue to be encouraged by right-wing organisations and sections of the media to think disadvantaged people lack backbone, are well-catered for, and are probably lazy and undeserving, if not downright dishonest in their claims for income support. It would be interesting to conduct a study to see how often these perceptions of low income earners are accompanied by references to or representations of children. While charities and NGOs continue to trade heavily on images of needy children to encourage donations for disadvantaged families, children, we suspect, tend to be conveniently neglected when attention focuses on whether families are eligible or 'deserving' of taxpayerfunded government benefits.

Yet the consequences of low incomes are plain enough for children and young people who live with parents reliant on social security payments. The impacts straddle many facets of wellbeing including physical, mental and emotional health, social wellbeing, and the capacity to deal with 
day-to-day challenges. One of the most overlooked concerns is what children themselves also learn from observing the treatment of their parents by government departments. A study by Grahame and Marston (2012), which involved interviews with sole supporting women who were receiving Centrelink payments, found that 'For nearly all of the women, experiences of misrecognition or disrespect, or both, were evident in the lack of recognition of their mother-worker identities, as well as in the sense of intrusion and control that was widely reported' (p. 84). It is difficult to imagine that children would not pick up on their parents' experiences and frustrations with government agencies in ways that would shape the children's attitudes and expectations in turn. Nor is this impact on children to be discounted because, as Grahame and Marston (2012, p. 77) note, 'People who experience stigmatisation repeatedly internalise negative self-images and in turn this impacts on their ability to consider themselves as having a capacity to shape their life chances and life choices in the economic and social sphere.' The loss of agency that goes with trying to penetrate convoluted, arbitrary, anonymous bureaucratic processes would not make it easy for parents to offer children a sense of capacity to shape their lives or to feel confident about the future, when parents are struggling themselves.

Such impacts on families' confidence and motivation to seek assistance compound the many other forms of disadvantage that affect children and families on low incomes. Poorer health and education outcomes for low income families have been extensively documented over the years, covering issues as diverse as mental health and nutrition to early language development. In the UK, for example, there have been requirements for sole supporting mothers to return to work when children reach a certain age. Mothers have been found to have an increased susceptibility to mental health issues due to this pressure (Katikireddi, Molaodi, Gibson, Dundas, \& Craig, 2017). In the USA, authors investigating the impacts of changes to income support concluded 'the lack of resources for teen parents helps explain their accumulating developmental and health disparities' (Hardy, Smeeding, \& Ziliak, 2018). Similarly in Australia, BrennanOlsen and Friel (2018, n.p.) acknowledged in correspondence to the Medical Journal of Australia that:

With few exceptions, people who are more socially disadvantaged have worse health than their advantaged counterparts - a paradigm known as the social gradient of health. Despite increased need, socially disadvantaged individuals are less likely to access health care compared with advantaged people.

The attendant issue is that lack of income not only limits families' access to health services and medicines, but in doing so serves to discourage help-seeking behaviours by parents, which children learn to regard as normal. Family culture and attitudes are powerful, orienting children and young people to ideas and approaches that are not always helpful. For instance, people in low income groups are more likely to be overweight or obese (Overcash et al., 2017) due to a number factors that can include the cheapness of less nutritious foods and convenience foods, and unwillingness on the part of parents to declare their financial difficulties in order to access food banks. Although outside observers may blame weight problems on poor choices, a weight issue in itself, can reflect a level of disengagement or hopelessness about being able to achieve and maintain good health.

In theory, education might serve to ameliorate some aspects of this kind of disadvantage, except that the impacts of disadvantage extend to children's schooling too. In Australia, state schooling is no longer strictly 'free', and parents on low or unpredictable incomes due to difficulties with social security payments can be left struggling to meet all the costs associated with schools' expectations, class activities and excursions. There are pressures on parents to ensure that children have laptops, uniforms and sportswear, and children without these resources tend to stand out in a manner that excludes them from their peer group. Moreover, the educational disadvantage of children from low income families often commences, insidiously, before schooling even begins. Studies such as that by Neuman, Kaefer and Pinkham (2018) in the USA have identified language deficits that can affect children by their preschool years, arising, in part, from low income families tending to live in areas where there is existing low educational attainment. Children living in poverty are also likely to be living in areas where housing is cheap and most households share the experience of poverty. As Neuman et al. (2018, p.115) state:

In neighborhoods of concentrated poverty, individual families must cope not only with their own poverty, but also with the economic deprivation of the many families who live nearby. This spatial concentration can act to magnify economic disadvantage and exacerbate its effects.

Poor language skills impact on the poor the world over, and do make it difficult for children and young people to compete as young adults for jobs that require literacy as well as emotional literacy and language skills.

Finally, if issues such as these are insufficient to prompt governments to heed the matter of intergenerational disadvantage and its effects, they might consider the consequences for future civic engagement when government agencies are perceived as unreliable and likely leave families feeling less aided than frustrated. Children learn from seeing parents and family members regularly disturbed by difficulties dealing with bureaucracies and their regulations, particularly in the case of social security organisations. They hear and observe emotions like anger, helplessness and desperation, and learn simply that the system is not to be trusted - that gaining access to welfare benefits has less to do with fairness and the delivery of stated entitlements, than people's status and plain luck. When government agencies are no longer trusted to deliver, confidence in elected representatives diminishes 
too. It is perhaps not a coincidence that rising inequality is coinciding with the rise of populist political parties, and, in Australia's case, with trust in politicians reaching new lows (Cameron \& McAllister, 2016). We should not neglect the consequences for democratic integrity and social cohesion when intergeneration poverty becomes entrenched, or when growing numbers of people are left disillusioned by the rules and processes that have to be appeased in order to obtain financial assistance for survival.

Last year, the Australian Government Department of Human Services Annual Report 2016-2017 (Commonwealth of Australia, 2017, p.181) noted an increase in the number of complaints about Centrelink:

In 2016-17 the department recorded 184,553 feedback contacts about Centrelink services, of these 168,709 were complaints. The top three complaints by volume were:

- dissatisfaction with a claim, application or assessment process, including waiting too long, not updated on progress and multiple contacts to progress (28.2 per cent). Even though most Centrelink claims are processed in under 35 days, in some cases it may take longer, as the department must consider all relevant information when processing claims and on occasion this results in people complaining about the process or delay. Age Pension claims generally take longer to process as the department has to assess often complex income and asset information.

- dissatisfaction with a decision, outcome or payment, including a payment not being received, a cancellation or suspension and waiting too long (25.2 per cent)

- difficulties with phone services, including complaints about hold wait times, engaged signals and call disconnections (16.2 per cent). At certain times on certain days the department's telephone lines experience peak periods and some people experience a longer wait and provide the department with feedback on their experiences.

We feel these figures could be significantly greater given recipients of welfare benefits sometimes fear they may be penalised for lodging complaints, while others, including those who shared their comments with Children Australia, indicated they had not lodged complaints because of the extra time involved in doing so.

There is no doubt that many issues need to be resolved to ensure an adequate income for all families. As Harris, Fetherston and Calder (2017) write: 'Low socio-economic status is a major risk factor for poor health. Policies which address the health impacts of social and economic conditions will significantly improve all aspects of society and contribute directly to a prosperous, productive and healthy nation.' This leads to the consideration of a different way in which families and individuals, and particularly children and young people, could be supported and afforded income security - a Universal Basic Income (UBI). Controversial? Indeed it is, but there is a growing body of evidence to suggest that some form of UBI might resolve some of the issues that are raised in discussions about eligibility for payments, delays in applications, and expenditure on welfare surveillance. Much more important in our opinion, a UBI might allow us to do away with the deserving/undeserving dichotomy, and the disruption in households that affects children when parents are unable to secure an income or are penalised for failing to meet obligations. The UBI will certainly be a topic to pursue in the future.

The selection of papers presented in this issue of Children Australia are varied in both topic and content type. We begin with an exchange of ideas between Frank Ainsworth and Martha Holden with Susan Tregeagle, in the form of a letter to the editor. There is little doubt that the issue of children living in care is a complicated matter filled with an array of complex factors. As such, it attracts researchers and practitioners who are passionate about the experiences of young people in care and who hold divergent opinions on what best practice might look like. Three such practitioners have shared their opinions here. As editors of Children Australia we are keen to promote robust discussions about the various topics raised by the authors who take the time to contribute to the journal. With both our personal and professional opinions often differing, we think it is important to make a space where differences in opinion and experience can be shared and debated. Frank and Martha have shared their contested views on issues raised by Susan and, in turn, Susan has reiterated some of her points and responded to their observations. We hope that this is one of many conversations that the content of this journal is able to promote.

This is followed by two commentaries. The first, written by Charles Bachand and Nikki Djak, was submitted as part of a proposed special issue that explored the ways that children's right to rest, leisure and play is actualised or compromised in their daily lives. Unfortunately, we were unable to assemble enough content for that special issue, however Charles and Nikki wrote a thought provoking paper on the parallels between Stockholm syndrome and abusive coach-athlete relationships which was well worth publishing. Drawing on theories of Stockholm syndrome, which results in victims being subservient to their captor's demands, the authors talk about the victimisation of some young athletes. They suggest that young athletes, like victims experiencing Stockholm syndrome, can reach a point in which they rationalise, defend and sympathise with the actions of abusive coaches. When thought of in these terms this quite obviously contravenes the tenets outlined in the United $\mathrm{Na}-$ tions Convention on the Rights of the Child (1989) with regard to children's right to appropriate play and safety.

The second commentary is by Frank Ainsworth and Patricia Hansen. They review recent legislative and programme methods implemented by the NSW child protection system to try and reduce the number of children in state care. As a very practical measure they also provide their own guidelines or advice on how to coach parents about children's needs and navigating the child protection system. For many 
parents of children entering the child protection system for the first time there is often little or no knowledge of the processes or what is expected of them. Not only might this be a foreign space for many parents, they are often thrust into it without any warning or support, which can make for a stressful and even volatile experience. Based on their years of experience in this setting, Frank and Patricia offer advice for parents and child protection workers about ways to manage this process.

Following these practice commentaries are two papers by Rachel Breman, Ann MacRae and Dave Vicary from Baptcare. The authors have written a series of papers examining the nature of family violence in kinship care based on a study they undertook in 2017 with kinship carers from Victoria, Australia. Along with the first article published earlier this year, these two papers provide insight into the experiences of kinship families in which violence occurs. The first one, titled 'The hidden victims' - Family violence in kinship care in Victoria, reports on the experiences of kinship carers as 'hidden victims' of family violence. Based on a qualitative study in which they sought the views and experiences of kinship carers, they found that many carers are subjected to violence from a family member of the child they are caring for, which has a dramatic negative impact on them and their family. They suggest that some carers sought support to help deal with the violence, but found varied success with these attempts. Their second paper, titled Child perpetrated family violence in kinship care in Victoria, as the name suggests, examines the experiences of families who provide kinship care to children who themselves perpetrate violence. With a focus on child-perpetrated violence directed towards carers, the authors found that aggressive behaviours directed towards carers often occurred early in the placement and it was a frequent occurrence for some families. This violence had an impact on the carer's health and wellbeing and impacted on the placement stability. Both papers describe the approach taken by Baptcare to address family violence in its kinship care programmes.

Moving beyond individual or personal experiences of child maltreatment and into the realm of public policy, Celine Harrison, Maria Harries and Mark Liddiard have undertaken a qualitative content analysis of debates in the West Australian Parliament from 2006 that related to child welfare and child deaths. They found that statistics about child deaths were used in ways that promoted 'blame, fear, risk and an individual responsibility' by framing child maltreatment as simply a moral crime, without recognition of the nuanced and complex nature of this social issue. The authors advise professionals in field, chief amongst them researchers, practitioners and policy makers, to debate the topic with greater recognition of its complexity beyond moral judgement and blame of individuals.

The final article is by Abul Khan, Debra Miles and Abraham Francis, and also adds to the topic of child maltreatment and protection. The authors' aim was to report on families' experiences of child protection services and explore these within an empowerment framework. Based on interviews with ten families they draw our attention to families' experiences of the child protection system. Specifically, they report on participants' experiences in relation to engagement and the alienation they felt in regard to their interactions with service providers in all stages of intervention.

This issue ends with two reviews by Frank Ainsworth. Frank has reviewed a research report by Jeremy Summut called Resetting the pendulum: Balanced, effective, accountable child protection systems and adoption reform In Australia and a book called The three pillars of transforming care: Trauma and resilience in the other 23 hours by Howard and John Seita.

\section{References}

Australian Council of Social Services (2016). Poverty in Australia 2016. Strawberry Hills, NSW: Australian Council of Social Service. Retrieved from https://45hbzy11zfk22hzfapc5zhem-wpengine.netdnassl.com/wp-content/uploads/2016/10/Poverty-inAustralia-2016.pdf

Brennan, F. (2018, April 30). Newstart needs a new start. Eureka Street. Retrieved from https://www.eurekastreet.com.au/ article.aspx?aeid $=55274$

Brennan-Olsen, S., \& Friel, S. (2018). Letter to the editor. Medical Journal of Australia, 208(10), 461. doi: 10.5694/mja17.01215

Cameron, S., \& McAllister, I. (2016). Trends in Australian political opinion: Results from the Australian election study 1987-2016. Canberra, ACT: Australian National University. Retrieved from http://legacy.ada.edu.au/ ADAData/AES/Trends\%20in\%20Australian\% 20Political\%20Opinion\%201987-2016.pdf

Centre for Poverty Research (2017). What is the current poverty rate in the United States?: Current estimates on poverty in the U.S.? Retrieved from https://poverty.ucdavis.edu/ faq/what-current-poverty-rate-united-states

Commonwealth of Australia (2017). Australian Government Department of Human Services Annual Report 2016-2017. Canberra, ACT: Commonwealth of Australia.

Conifer, D. (2018, January 23). Centrelink call wait times grow, with some clients waiting an hour on hold. $A B C$ News. Retrieved from http://www.abc.net.au/news/ 2018-01-23/centrelink-call-wait-times-balloon/9351450

Grahame, T., \& Marston, G. (2012). Welfare-to-work policies and the experience of employed single mothers on income support in Australia: Where are the benefits? Australian Social Work, 65(1), 73-86. doi: 10.1080/0312407X.2011.604093

Hardy, B., Smeeding, T., \& Ziliak, J. (2018). The changing safety net for low-income parents and their children: Structural or cyclical changes in income support policy? Demography, 55, 189-221. doi: 10.1007/s13524-017-0642-7

Harris, B., Fetherston, H., \& Calder, R. (2017). Australia's Health Tracker by Socio-Economic Status 2017. Melbourne, Vic.: Australian Health Policy Collaboration in collaboration with Victoria University. 
Karp, P., \& Knaus, C. (2018, April 4). Centrelink robo-debt program accused of enforcing 'illegal' debts. The Guardian. Retrieved from https://www.theguardian.com/australianews/2018/apr/04/centrelink-robo-debt-programaccused-of-enforcing-illegal-debts

Katikireddi, S.V., Molaodi, O., Gibson, M., Dundas, R., \& Craig, P. (2017). Evaluating the health impacts of restrictions to income support for lone parents: A natural experiment study using understanding society. Abstract OP76. Journal of Epidemiology Community Health, 71(Suppl), A38. doi:10.1136/jech-2017-SSMAbstracts.75

Loach, K. (Director). (2016). I, Daniel Blake. [Motion Picture]. UK: Sixteen Films, Why Not Productions and Wild Bunch.
Neuman, S., Kaefer, T., \& Pinkham, A. (2018). A double dose of disadvantage: Language experiences for low-income children in home and school. Journal of Educational Psychology, 110(1), 102-118.

Office for National Statistics (2017). Persistent poverty in the UK and EU: 2015. Retrieved from https://www.ons.gov.uk/ peoplepopulationandcommunity/ personalandhouseholdfinances/incomeandwealth/ articles/persistentpovertyintheukandeu/2015

Overcash, F., .... Reicks, M. (2017). Positive impacts of a vegetable cooking skills program among low-income parents and children. Journal of Nutrition Education and Behavior, Retrieved from https://doi.org/10.1016/j.jneb.2017.10.016 